\title{
Prediction of Total Antioxidant Activity of Prunella L. Species by Automatic Partial Least Square Regression Applied to 2-Way Liquid Chromatographic UV Spectral Images
}

\section{Ahmet Kemal Aloglu ${ }^{1}$, Peter de B. Harrington ${ }^{1 *}$, Saliha Sahin ${ }^{2}$, Cevdet Demir $^{2}$}

${ }^{1}$ Center for Intelligent Chemical Instrumentation, Clippinger Laboratories, Department of Chemistry and Biochemistry, Ohio University, Athens, $\mathrm{OH} 45701$, USA.

${ }^{2}$ Department of Chemistry, Faculty of Science and Arts, University of Uludag, Bursa 16059, Turkey.

*Author to whom correspondence should be addressed; E-Mail:

peter.harrington@ohio.edu; Tel.: +1-740-994-0265; Fax: +1-740-593-0148.

Abstract Four different data representations were evaluated for the determination of the total antioxidant activities of four different Prunella L. species, which are Prunella vulgaris, Prunella grandiflora, Prunella laciniata, and Prunella orientalis Bornm. Three different antioxidant assays, 2,2'-azino-bis(3-ethylbenzothiazoline-6sulphonic acid) (ABST), 2,2-diphenyl-1-picrylhydrazyl (DPPH), and Folin-Ciocalteu (FC) reagent measured the total antioxidant activity and phenolic content of the four Prunella L. species that were extracted with 12 different solvent systems. The data set of 48 Prunella L. extracts was collected by high-performance liquid chromatography (HPLC) with ultraviolet diode array detection. The prediction of total antioxidant activity of Prunella L. species by super partial least square (sPLS) 
regression was obtained using four different representations of the data; the entire two-way chromatographic-spectral images, the average UV spectra, the total absorbance chromatogram, , the lambda $\max \left(\lambda_{\max }\right)$ chromatogram. The coefficients of determination $\left(R^{2}\right)$ for the entire two-way chromatographic-spectral images (the ABST $(0.943 \pm 0.008)$, the DPPH $(0.91 \pm 0.01)$, and the FC $(0.963 \pm 0.006))$ indicated good accuracy for predicting antioxidant activities. The three different wet chemical assays are known to yield different values so it is advantageous to estimate the three separate values with a single LC measurement. The entire two-way chromatographic-spectral images have been used to the first time for calibration. Acidic hexane, as an extraction solvent, gave the least root mean square error of prediction (RMSEP) for the two-way chromatographic-spectral images, so it would be the best solvent for modeling antioxidant activities.

Keywords: Prunella, ABST, DPPH, Folin-Ciocalteu, antioxidant, super partial least squares regression (sPLS), two-way calibration, HPLC with UV detection.

\section{Introduction}

There has long been an interest in studying and evaluating different plant species for their potential health and medicinal benefits. More frequently, plants containing high concentrations of phytochemicals such as flavonoids, phenolic acids, and terpenes have received much attention due to their potential antioxidant properties that have been observed ${ }^{1}$. Antioxidant can be considered as the general term for these compounds which either inhibit the formation of free-radicals or consumes them ${ }^{2}$. Free radicals may initiate chain reactions that cause the degradation of biomolecular pathways, which subsequently result in cancers and 
heart diseases ${ }^{3-6}$. Because antioxidants are thought by some to scavenge free radicals, there is interest in characterizing the antioxidant capacity of plants and foods. Such species include the berry family of fruits, artichoke heart, and walnuts ${ }^{6}$, all of which contain phenolic compounds which have been evaluated and shown as functional forms of chemical protection from diseases, displaying anticarcinogenic and anti-mutagenic traits, for example ${ }^{2,7}$. However, overdose consumption of antioxidant-related diets may have no benefit for prevention of disease for human health ${ }^{8}$, and surprisingly may increase the probability of facing some health-issues for certain people ${ }^{1}$. There is no clear-cut answer if antioxidantrelated diets make some contributions to promoting human-health ${ }^{9}$.

Here, from the family of Lamiaceae as medicinal herbs, Prunella L. species have been studied for their antioxidant potentials, and their extracts have been measured to construct models to predict antioxidant activity. The Prunella L. species used in this study are $P$. vulgarus, grandiflora, laciniata, and orientalis Bornm. One of these species, Prunella vulgarus, is considered as an inhibitor of the human immunodeficiency virus (HIV) in early and recently published papers ${ }^{5,10-11}$. Many different standard procedures exist for evaluating antioxidant activity of botanicals ${ }^{12-13}$. Three antioxidant assays were applied to extracts from the Prunella L. species. The first one is 2,2-azino-bis-(3-ethylbenzothialozine-sulfonic acid) $(A B S T)$, which creates a radical cation $\left(\mathrm{ABST}^{\circ+}\right)$ with an oxidizing agent, such as met-myoglobin ${ }^{14}$. The second assay uses 2,2-diphenyl-1-picrylhydrazyl (DPPH), with the effect determined through a combination of its concentration, the solvent used, the $\mathrm{pH}$ value of the mixture, and the length of time $\mathrm{e}^{15-16}$. The third antioxidant 
assay involves Folin-Ciocalteu (FC) reagent, which is referred to as a total phenolic assay and is a mixture of phosphomolybdate and phosphotungstate, which acts as a colorimetric assay for phenolic and polyphenolic antioxidants in foods and supplements ${ }^{12}$. Both the ABST and the DPPH are referred to as Trolox equivalent antioxidant capacity (TEAC) assays while the FC method is a gallic acid equivalent (GAE) assay, with all three being based on electron transfer ${ }^{12}$. Collectively, these are considered as non-specific analytical methods, and therefore it is not possible for their results to determine an accurate measure of the antioxidant capacity value of the target species as each method utilizes a different procedure to collect its data ${ }^{17}$. So it is difficult to compare the results from different research groups who are not using precisely the same method ${ }^{12}$. A study by Bolling et al. tried to report total antioxidant activity by a single dilution factor to introduce consistent results for different antioxidant assays of different fruit juices, but failed due to the inconsistent measures of total antioxidant activity values, and concluded that a standardized total antioxidant activity assay was immediately needed for an operative comparison ${ }^{18}$. However, our approach seeks to generate reliable measures for each assay from a single chromatographic run.

Because these three assays lack analytical specificity, they are generally not used with the aim of identifying relationships between specific antioxidant-related compounds and health-outcomes ${ }^{17}$. Consequently, if the study of causal relationships is a requirement, there is a need to use a specific analytical method to ascertain any ensuing health benefits associated with specific antioxidant-related compounds. In this case, the identification, isolation, and evaluation of individual antioxidant-related compounds in target food and plant samples may be 
accomplished by any one of several analytical methods, such as liquid chromatography and mass spectrometry (LC-MS) and high performance liquid chromatography (HPLC). HPLC with ultraviolet diode array detection (HPLC-UVDAD), for example, was used for assaying the 48 Prunella L. extracts. The specific and comparable findings from such procedures may be crucial for reporting any health outcomes associated with antioxidant intake, and in developing future treatments or preventative steps for diseases ${ }^{17}$.

Multivariate calibration is an alternative approach which can be used to predict the total antioxidant activity directly from spectra or chromatographic measurements, and it saves considerable time compared to the aforementioned procedures involving the ABST, the DPPH, and the FC wet-chemical assays. Partial least squares (PLS) regression is one of the most popular multivariate calibration methods ${ }^{19-21}$, and this works by modeling the relationships between an independent block of measurements $\mathbf{X}$ and a dependent block of properties $\mathbf{Y}^{21}$. This chemometric technique is based on modeling $n$ independent variables of $\mathbf{X}$ (predictor variables) and / dependent variables of $\mathbf{Y}$ (responses), and comprises a set of components that characterize the covariance between the blocks $\mathbf{X}$ and $\mathbf{Y}^{19-}$ 21.

Pioneering work has demonstrated that using two-way chromatographic spectral images retains the greatest amount of information and is the best representation for classification ${ }^{22-27}$. This paper demonstrates that the two-way chromatographic spectral images may be used for calibration as opposed to other standard methods such as the total absorbance chromatogram. In the study, four different 
representations of the data were evaluated with respect to their efficacy for predicting the antioxidant activity: the two-way chromatographic-spectral images, the average UV spectrum, the total absorbance chromatogram and the lambda max $\left(\lambda_{\max }\right)$ chromatogram. This paper is the first time that the two-way chromatographic-spectral images have been used to construct a calibration model although other work has been published on peak clusters and selected regions of the chromatogram. For authentication of complex materials, it makes sense to use the entire chromatographic regions because in chemical profiling, the identity of the active compounds and their peaks may be unknown or variable.

\section{Theory}

\subsection{Data Preprocessing}

The data were not normalized because normalization worsened the prediction rates. However, because the volume that was injected was carefully controlled by the LC sample loop normalization of the chromatograms was unnecessary. Furthermore, because the goal of the measurement is to determine the absolute antioxidant capacity from different extracting solvents, normalization would confound the variations that are to be measured.

Retention time alignment was performed to correct drift in the chromatographic peaks. Peak drift was ascertained by comparing the UV spectra among peaks in the same retention time window. After alignment, the square root transform of the absorbances in the two-way chromatographic-spectral images improved the prediction rates of the models by inflating the relative importance of the smaller 
features in the chromatographic data and was used consistently throughout the study.

The two-way chromatographic-spectral images were aligned using a two-step polynomial interpolation procedure. First, the total absorbance chromatograms for each solvent used for extraction were very different from each other. The species difference was a minor variation. The two-way chromatographic-spectral images for each of the 12 solvents were aligned by maximizing the correlation with the first occurring chromatogram image in the solvent group using a $5^{\text {th }}$ order polynomial for interpolation.

The second step, used two peaks that were common to all the chromatograms located at 5.4 and 25.2 min to align among the 12 solvent groups by using a simple linear interpolation. For this step, the chromatogram images were aligned with respect to the first object in the data set. This approach worked quite well as can be seen in Figure 1 and Figure 2.

\subsection{Partial Least Squares Regression}

Partial least squares (PLS) regression is a widely used chemometric technique that is usually applied to multivariate data ${ }^{28-29}$. PLS is based on determining the inner relationship or covariance between the column-spaces of independent variables $\mathbf{X}$ and dependent variables $\mathbf{Y}$. The independent matrix comprises one of the four representations of the LC data and the dependent matrix comprises the measured antioxidant activities. All four representations comprised 48 samples. The four species of Prunella were extracted with 12 different solvents to furnish the 48 samples. 
The PLS procedure was modified so that it would automatically determine the optimum number of latent variables or components ${ }^{30}$. The PLS model internally applied bootstrap Latin partitions ${ }^{31}$ with 4 partitions and 20 bootstraps to only the calibration set of data. From the internal bootstrap of the calibration set, the number of latent variables that yielded the lowest average prediction was then used to build a model from the entire calibration set. This algorithm provides a parameter free version of PLS that is affectionately named Superpls (sPLS).

\subsection{The Bootstrapped Latin-Partition}

Separate from the internal bootstrap of sPLS, an external bootstrap with Latin partitions was also applied for validating the PLS model and comparing the four different data representations. The bootstrapped Latin partitions (BLPs), given in detail elsewhere ${ }^{31}$, is a method for evaluation of calibration based on crossvalidation that seeks to characterize the variances introduced to chemometric models by training and prediction set selection. This method is advantageous compared to other bootstrapping methods because the distribution of levels (i.e., activities) are similar between the model building and prediction sets, and each object is used only once for prediction so the results may be pooled, so that every object in the data set is used once for prediction for each bootstrap. The pooled results are then averaged across the bootstraps and provide precision measures in the form of $95 \%$ confidence intervals. Because the results from this outer bootstrap procedure are never used to refine the method or estimate parameters, this outer bootstrap applies several hundred external validations (i.e., 4 partitions

and 100 bootstraps). The external bootstrap procedure provides a general measure 
of the prediction error with bounds so that any repeat of the experiment will yield average errors that fall within the bounds.

\section{Materials and Methods}

\subsection{Plant materials and preparation of the extracts}

Four different Prunella L. species (Prunella vulgaris L. in Keles, Bursa, Prunella laciniata L. in Cali-Inegazi, Bursa, Prunella grandiflora L. in Edremit, Balikesir, Prunella orientalis Bornm. in Kemer, Antalya) were collected from locations in Turkey in June-July of 2009. The detailed sample preparation is given in references ${ }^{32-33}$.

\subsection{Reagents}

The reagents purchased for the ABST were from Fluka (Buchs, Switzerland), for the DPPH, the FC, and Trolox [( \pm )-6-hydroxy-2,5,7,8-tetramethylchroman-2-carboxylic acid] from Sigma-Aldrich (St. Louis, MO, USA), and for analytical grade of hydrochloric acid, HPLC grade of methanol, butanol, ethyl acetate, acetonitrile, hexane, formic acid, ascorbic acid, and caffeic acid from Merck (Darmstadt, Germany).

\subsection{Data collections}

High-performance liquid chromatography (HPLC) with UV detection was applied to measure 48 Prunella extracts ${ }^{32-33}$. The average values of two replicates of the antioxidant measurements were reported in the previous work and are used to construct the calibration models.

\section{Experimental Section}


Calibration models to predict the total antioxidant activity of Prunella L. species were built using an automated form of PLS. This algorithm is affectionately named super PLS (sPLS). For each set of calibration data, an internal bootstrap Latin partition (BLP) is used ${ }^{31}$. For this study, 20 internal bootstraps were used with 4 partitions that are similar to the external bootstrap procedure is described below.

The measured total antioxidant activity of Prunella L. species comprise matrix $\mathbf{Y}$, and the representations of the chromatographic and UV data comprise matrix $\mathbf{X}$. Bootstrapping is a resampling technique performed to generate a generalized measurement of prediction accuracy with confidence intervals. The data-set was divided into 4 equal groups because there were 48 samples collected from 4 different Prunella L. species. The partition ratio of the data-set was a 3:1, so that $75 \%$ of the data was used for calibration and $25 \%$ of the data is used for prediction. The average coefficients of determination $R^{2}$ were calculated from the 100 bootstraps.

The preprocessing of the data only used the square root transformation. Average root mean square errors of prediction (RMSEP) were calculated from the 100 bootstraps as well. Confidence intervals were calculated from the standard deviations of the RMSEP of each bootstrap.

The two-way chromatograpgic-spectral representations were unfolded into vectors so that they would form a data matrix for which each row corresponded to the sample and each column corresponded to an absorbance measurement made at a specific wavelength and retention time. This data matrix had 48 rows and 139,072 
columns. The lambda $\max \left(\lambda_{\max }\right)$ chromatogram is simply the maximum absorbance for each UV spectrum plotted with respect to retention time. All evaluations were made using MATLAB R2016a (The MathWorks Inc., Natick, MA). The computer operated under Microsoft Windows 7 Enterprise Edition 64-bit Enterprise Edition (Redmond, WA) and was implemented on a computer with an Intel Core ${ }^{\mathrm{TM}}$ i7 $940 \mathrm{CPU}$ Extreme Edition operating at $2.93 \mathrm{GHz}$ with $8.00 \mathrm{~GB}$ RAM. Total run time for the total antioxidant prediction of Prunella L. species was $\sim 3 \mathrm{~h}$ of CPU time for all the four representations for the 10 bootstraps.

\section{Results and Discussion}

The total antioxidant activity and the total phenolic content of the Prunella L. species were previously determined with the analysis of 12 different extraction solvents by three different antioxidant methods, the ABST, the DPPH, and the FC methods. The total antioxidant activity and phenolic content of the Prunella L. species from the ABST, the DPPH, and the FC methods were used from the

published articles ${ }^{32-33}$. These antioxidant activities are reported in Table 1. Based on the 4 different Prunella L. species, along with 12 different extraction solvents, the total antioxidant activity by the ABST and DPPH methods were measured as Trolox equivalent (TE). The values ranged from $0.44 \pm 0.01$ to $344 \pm 2 \mathrm{mg} \mathrm{TE} / \mathrm{g}$ of dried plants and from $0.05 \pm 0.01$ to $256 \pm 3 \mathrm{mg} \mathrm{TE} / \mathrm{g}$ dried plants, respectively for the ABST and the DPPH. The total phenolic content was measured as the gallic acid equivalent (GAE) by the FC method, and the values ranged from $1.0 \pm 0.2$ to $87 \pm 1$ $\mathrm{mg} \mathrm{GAE} / \mathrm{g}$ of the dried plant material. From Table 1, the most efficient solvent was acidic methanol for extracting the phenolic compounds because it yielded the greatest antioxidant activities ranging from $219 \mathrm{mg} \mathrm{TE} / \mathrm{g}$ dried sample to $344 \mathrm{mg}$ 
$\mathrm{TE} / \mathrm{g}$ dried sample. However, acidic ethyl acetate gave the highest extraction efficiency for the phenolic compounds (Table 1).

Figure 3 is a surface plot of the chromatographic and UV spectral image of the Prunella grandiflora L. extracted with acetonitrile. High absorbance can be clearly seen at the retention time of 5 min where the wavelength ranged between 220-275 $\mathrm{nm}$ in Figure 3. Figure 4 gives the total absorbance chromatograms and the average UV spectra across the retention times of the 4 different Prunella L. species prepared with the 12 extraction solvents as reported in Table 1 . The UV spectraError! Reference source not found. (bottom) in Figure 4 comprise 48 different Prunella L. samples. Prunella vulgarus L. when extracted with water gave different peaks than the other species and solvents.

The PLS prediction of antioxidant activity of the set of 4 Prunella L. from four different representations; the two-way chromatographic-spectral images, the averaged UV spectrum, the total absorbance chromatogram and the lambda max $\left(\lambda_{\max }\right)$ chromatogram. The coefficients of determination $\left(R^{2}\right)$ of the predicted and measured (experimental results in Table 1) antioxidant activities for the four different representations are reported in Table 2 . The results are both before and after retention time alignment. Thus, the same trends are observed among the coefficients of correlation $R^{2}$ for the four different representations.

The prediction results given in Figure 5 were obtained from the two-way chromatographic-spectral images representations after retention time alignment. As clearly seen, the $R^{2}$ values vary among the three different assays. The best correlation result were obtained for the FC method that gave an average $R^{2}$ of 
$0.969 \pm 0.002$ before retention time alignment, and $0.963 \pm 0.006$ after retention time alignment. The ABST and the DPPH methods before retention time alignment gave an average $R^{2}$ of $0.936 \pm 0.003$ and $0.911 \pm 0.003$, respectively. Retention time alignment had a slightly same effect on prediction of antioxidant activity of Prunella L. species with the ABST and the DPPH methods giving an average $R^{2}$ of $0.943 \pm 0.008$ and $0.91 \pm 0.01$, respectively, for the two-way chromatographicspectral images representation.

Often, the average or summed spectrum of a chromatogram is used because retention time drift and consequent alignment step can be mitigated by use of this representation. Figure 6 is the predicted and observed antioxidant and phenolic content values of Prunella L. species for the UV spectral representation after retention time alignment. The decrease in predictability indicates that the UV spectral representation is insufficient to model the antioxidant content of the plant material. The average $R^{2}$ based on the UV spectra for the ABST and the DPPH methods before retention time alignment are $0.48 \pm 0.04$ and $0.60 \pm 0.03$, respectively. The significant improvement in correlation values by 0.26 for ABST and by 0.16 for DPPH are observed after retention time alignment, but still quite low as compared to other correlation values of other representations. However, the UV spectral representation may be sufficient to model the phenolic content. The correlation values of the FC method were $0.919 \pm 0.003$ before retention time alignment and $0.944 \pm 0.006$ after retention time alignment providing an improvement for predicting the total phenolic content of Prunella L. 
The total absorbance chromatogram is another representation that was evaluated and the prediction results are given in Figure 7 after retention time alignment. For the ABST and the DPPH methods the average $R^{2}$ values are $0.873 \pm 0.005$ and $0.866 \pm 0.006$, respectively, before retention time alignment while the average $R^{2}$ of the ABST method after retention time alignment shows an increase with the value of $0.92 \pm 0.01$. The DPPH method also showed an increase in the average $R^{2}$ of $0.89 \pm 0.02$ after retention time alignment where it was the value of $0.866 \pm 0.006$ before retention time alignment. The FC method, on the other hand, gave an average $R^{2}$ of $0.957 \pm 0.002$ before retention time alignment, but showed a very slightly decrease with an average $R^{2}$ of $0.954 \pm 0.006$ after retention time alignment, but it still falls in to the confidence interval range.

The last representation was the lambda $\max \left(\lambda_{\max }\right)$ chromatogram after retention time alignment presented in Figure 8 . The ABST method gave the better average $R^{2}$ values than both the DPPH and the FC methods with both before and after retention time alignment. The average $R^{2}$ value of the ABST method is $0.93 \pm 0.02$ after retention time alignment while it was $0.935 \pm 0.002$ before retention time alignment. The DPPH method showed a decreasing trend from from $0.903 \pm 0.004$ to $0.885 \pm 0.015$ after retention time alignment, but it still falled into the confidence interval range. However, the FC method resulted an increase in the average $R^{2}$ value from $0.885 \pm 0.004$ to $0.90 \pm 0.01$ after retention time alignment. Interestingly, the FC method resulted in the lowest average $R^{2}$ value with the lambda max $\left(\lambda_{\max }\right)$ chromatogram representation, where it yielded the best average $R^{2}$ value for the other 3 representations in the case of both before and after retention time alignment. 
Table 3 reports the RMSEPs for each representation for both before and after retention time alignment. The entire two-way chromatographic-spectral image yielded the lowest RMSEPs all 3 assays among four different representations with and without retention time alignment. After retention time alignment, ABST method shows a lowered RMSEP from $26.8 \pm 0.4$ to $24 \pm 1 \mathrm{mg} \mathrm{TE} / \mathrm{g}$ for the entire two-way chromatographic-spectral images. The DPPH method also showed an improvement by lowering the RMSEP from $20.6 \pm 0.3$ to $19 \pm 1 \mathrm{mg} \mathrm{TE} / \mathrm{g}$. The FC method, however, resulted in the confidance interval range of RMSEP for the same representation. The great improvements can be seen for UV spectra representation of ABST and DPPH methods where RMSEPs are decreased from $85 \pm 2$ to $50 \pm 5 \mathrm{mg}$ $\mathrm{TE} / \mathrm{g}$ and from $47 \pm 1$ to $31 \pm 3 \mathrm{mg} T E / \mathrm{g}$, respectively. A slight improvement from $9 \pm 1$ to $7.3 \pm 0.4 \mathrm{mg} \mathrm{GAE} / \mathrm{g}$ is also observed for FC method of UV spectra representation. The total absorbance chromatogram representation resulted a better RMSEP for DPPH method from $25.2 \pm 0.5$ to $21 \pm 1 \mathrm{mg} \mathrm{TE} / \mathrm{g}$ after retention time alignment while ABST and FC methods showed similar trend with before retention time alignment. Lambda $\max \left(\lambda_{\max }\right)$ chromatogram representation, on the other hand, gave the RMSEPs in the confidance intervals range of all three methods after retention time alignment. The FC method gave the lowest RMSEPs with respect to all data representations, with the minimum of $5.9 \pm 0.1 \mathrm{mg} \mathrm{GAE} / \mathrm{g}$ before retention time alignment and $5.9 \pm 0.4 \mathrm{mg} \mathrm{GAE} / \mathrm{g}$ after retention time alignment for the entire two-way chromatographic-spectral images. Based on the average prediction results in Table 3 and because the entire two-way chromatographic-spectral image representation contains the largest amount of 
information, it was selected to evaluate the extraction solvents and their corresponding antioxidant activities.

Table 4, Table 5 and Table 6 report the RMSEPs with confidence intervals for each solvent and four species obtained after retention time alignment from the two-way representations. Acidic hexane and acetonitrile had the lowest RMSEP for the ABST method in Table 4 for Prunella orientalis Bornm. at $2 \pm 1 \mathrm{mg} \mathrm{TE} / \mathrm{g}$, Prunella vulgarus L. at $3 \pm 2 \mathrm{mg} \mathrm{TE} / \mathrm{g}$ and Prunella grandiflora L. at $3 \pm 1$ and $3 \pm 2 \mathrm{mg} \mathrm{TE} / \mathrm{g}$, respectively. The lowest RMSEP of Prunella laciniata L. was observed with acetonitrile at $2 \pm 1 \mathrm{mg} \mathrm{TE} / \mathrm{g}$ for the ABST method. In Table 5, acidic hexane gave the lowest RMSEPs for Prunella grandiflora L. at $2 \pm 1 \mathrm{mg} \mathrm{TE} / \mathrm{g}$, Prunella orientalis Bornm. at $1 \pm 1 \mathrm{mg} \mathrm{TE} / \mathrm{g}$, and Prunella vulgarus $\mathrm{L}$. at $2 \pm 1 \mathrm{mg} \mathrm{TE} / \mathrm{g}$. In the case of Prunella laciniata L., the lowest RMSEP was observed both with acidic ethyl acetate and hexane at $3 \pm 2 \mathrm{mg} \mathrm{TE} / \mathrm{g}$. In Table 6 of FC method, the lowest RMSEPs for different Prunella species are varied with different solvents. Ethyl acetate and acidic hexane for Prunella grandiflora L. gave the lowest RMSEP at $1 \pm 1 \mathrm{mg} \mathrm{GAE} / \mathrm{g}$. and Prunella orientalis Bornm. gave the lowest RMSEPs with acidic hexane and acidic water at $1 \pm 1 \mathrm{mg} \mathrm{GAE} / \mathrm{g}$, and with ethyl acetate at $0.8 \pm 0.3 \mathrm{mg} \mathrm{GAE} / \mathrm{g}$. Acetonitrile, acidic butanol, acidic hexane and butano for Prunella vulgarus L. showed the lowest RMSEP at $2 \pm 1 \mathrm{mg} \mathrm{GAE} / \mathrm{g}$. For Prunella laciniata L., on the other hand, acidic hexane and acidic water gave both the lowest RMSEPs at $1 \pm 1 \mathrm{mg}$ GAE/g. The RMSEPs favored different solvents with respect to the different species, based on the RMSEP for the four species, the optimal extraction solvent for phenolic activity may depend on the species. 


\section{Conclusion}

Antioxidant activity assays of the ABST, the DPPH, and the FC were used to measure the total antioxidant activity and phenolic content of 4 different Prunella L. species with the use of 12 extraction solvents. The prediction values of the total antioxidant activity of these Prunella L. species were obtained by PLS calibration based on four different representations: the entire two-way chromatographic-UV spectral images, the average UV spectrum, the total absorbance chromatogram and the lambda max $\left(\lambda_{\max }\right)$ chromatogram. By comparing $R^{2}$ and RMSEPs results of these four different representations, the entire two-way chromatographic-UV spectral image gave the best predictions of the total antioxidant activity and phenolic content. The entire two-way chromatographic-UV spectral images are used for the first time for calibration. This representation preserves the most amount of information from the chromatographic run and multichannel detector.

Among the three assays, the FC method provided more reliable predictions both with the average $R^{2}$ values ranging between $0.90 \pm 0.01$ and $0.963 \pm 0.006$ after retention time alignment and with RMSEPs values ranging from $5.9 \pm 0.4 \mathrm{mg} \mathrm{GAE} / \mathrm{g}$ to $10 \pm 1 \mathrm{mg} \mathrm{GAE} / \mathrm{g}$ for all four representations after retention time alignment, with the average UV spectral representation performing the worst and representing the greatest loss of informing power. The ABST and the DPPH antioxidant activity assays failed to predict for this averaged UV spectrum representation.

Further evaluation using the prediction error demonstrated that acidic hexane may be the best solvent for all three assays if they are to be measured by LC-DAD. It can be concluded that acidic hexane combined with the entire two-way 
chromatographic-spectral representations provides a reasonable method to rapidly measure phenolic content and antioxidant measurements of Prunella extracts that may be extended to other botanical extracts.

\section{Acknowledgements}

The authors are thankful for Dr. Mengliang Zhang, Xinyi Wang, Xue Zhao, and Jacob Fadel for their helpful suggestions. The work was funded in part by contracts with the USDA-ARS and CannaPrint, LLC.

\section{References}

1. Holst, B.; Williamson, G., Nutrients and phytochemicals: from bioavailability to bioefficacy beyond antioxidants. Current Opinion in Biotechnology 2008, $19(2), 73-82$.

2. Yao, L.; Jiang, Y.; Shi, J.; Tomas-Barberan, F.; Datta, N.; Singanusong, R.; Chen, S., Flavonoids in food and their health benefits. Plant Foods For Human Nutrition 2004, 59 (3), 113-122.

3. AMES, B.; SHIGENAGA, M.; HAGEN, T., OXIDANTS, ANTIOXIDANTS, AND THE DEgenerative DiSeASeS OF AGING. Proceedings of the National Academy of Sciences of the United States of America 1993, 90 (17), 79157922.

4. HALLIWELL, B., FREE-RADICALS AND ANTIOXIDANTS - A PERSONAL VIEW. Nutrition Reviews 1994, 52 (8), 253-265. 
5. Kageyama, S.; Kurokawa, M.; Shiraki, K., Extract of Prunella vulgaris spikes inhibits HIV replication at reverse transcription in vitro and can be absorbed from intestine in vivo. Antiviral Chemistry \& Chemotherapy 2000, 11 (2), 157-164.

6. Dimitrios, B., Sources of natural phenolic antioxidants. Trends in Food Science \& Technology 2006, 17 (9), 505-512.

7. Huang, W.; Cai, Y.; Zhang, Y., Natural Phenolic Compounds From Medicinal Herbs and Dietary Plants: Potential Use for Cancer Prevention. Nutrition and Cancer-an International Journal 2010, 62 (1), 1-20.

8. Bjelakovic, G.; Nikolova, D.; Gluud, L.; Simonetti, R.; Gluud, C., Antioxidant supplements for prevention of mortality in healthy participants and patients with various diseases. Cochrane Database of Systematic Reviews 2012, (3).

9. Watson, J., Oxidants, antioxidants and the current incurability of metastatic cancers. Open Biology 2013, 3.

10. YAO, X.; WAINBERG, M.; PARNIAK, M., MECHANISM OF INHIBITION OF HIV1 INFECTION INVITRO BY PURIFIED EXTRACT OF PRUNELLA-VULGARIS. Virology 1992, 187 (1), 56-62.

11. Oh, C.; Price, J.; Brindley, M.; Widrlechner, M.; Qu, L.; McCoy, J.; Murphy, P.; Hauck, C.; Maury, W., Inhibition of HIV-1 infection by aqueous extracts of Prunella vulgaris L. Virology Journal 2011, 8. 
12. Huang, D.; Ou, B.; Prior, R., The chemistry behind antioxidant capacity assays. Journal of Agricultural and Food Chemistry 2005, 53 (6), 1841-1856.

13. Thaipong, K.; Boonprakob, U.; Crosby, K.; Cisneros-Zevallos, L.; Byrne, D., Comparison of ABTS, DPPH, FRAP, and ORAC assays for estimating antioxidant activity from guava fruit extracts. Journal of Food Composition and Analysis 2006, 19 (6-7), 669-675.

14. Walker, R.; Everette, J., Comparative Reaction Rates of Various Antioxidants with ABTS Radical Cation. Journal of Agricultural and Food Chemistry 2009, $57(4), 1156-1161$.

15. Cai, Y.; Sun, M.; Xing, J.; Luo, Q.; Corke, H., Structure-radical scavenging activity relationships of phenolic compounds from traditional Chinese medicinal plants. Life Sciences 2006, 78 (25), 2872-2888.

16. Sharma, O.; Bhat, T., DPPH antioxidant assay revisited. Food Chemistry 2009, $113(4), 1202-1205$.

17. Balentine, D.; Dwyer, J.; Erdman, J.; Ferruzzi, M.; Gaine, P.; Hamly, J.; Kwik-Uribe, C., Recommendations on reporting requirements for flavonoids in research. American Journal of Clinical Nutrition 2015, 101 (6), 1113-1125.

18. Bolling, B.; Chen, Y.; Kamil, A.; Chen, C., Assay Dilution Factors Confound Measures of Total Antioxidant Capacity in Polyphenol-Rich Juices. Journal of Food Science 2012, 77 (2), H69-H75. 
19. GARTHWAITE, P., AN INTERPRETATION OF PARTIAL LEAST-SQUARES. Journal of the American Statistical Association 1994, 89 (425), 122-127.

20. Ruiz, M.; Mujica, L.; Berjaga, X.; Rodellar, J., Partial least square/projection to latent structures (PLS) regression to estimate impact localization in structures. Smart Materials and Structures 2013, 22 (2).

21. Wold, S.; Sjostrom, M.; Eriksson, L., PLS-regression: a basic tool of chemometrics. Chemometrics and Intelligent Laboratory Systems 2001, 58 (2), 109-130.

22. Lu, Y.; Chen, P.; Harrington, P. B., Comparison of differential mobility spectrometry and mass spectrometry for gas chromatographic detection of ignitable liquids from fire debris using projected difference resolution. Anal Bioanal Chem 2009, 394 (8), 2061-2067.

23. Rearden, P.; Harrington, P. B.; Karnes, J. J.; Bunker, C. E., Fuzzy rulebuilding expert system classification of fuel using solid-phase microextraction two-way gas chromatography differential mobility spectrometric data. Anal Chem 2007, 79 (4), 1485-1491.

24. Lu, Y.; Harrington, P. B., Forensic application of gas chromatography Differential mobility spectrometry with two-way classification of ignitable liquids from fire debris. Anal Chem 2007, 79 (17), 6752-6759.

25. Sun, X. B.; Zimmermann, C. M.; Jackson, G. P.; Bunker, C. E.; Harrington, P. B., Classification of jet fuels by fuzzy rule-building expert systems applied 
to three-way data by fast gas chromatography-fast scanning quadrupole ion trap mass spectrometry. Talanta 2011, 83 (4), 1260-1268.

26. Wang, Z. F.; Chen, P.; Yu, L. L.; Harrington, P. D., Authentication of Organically and Conventionally Grown Basils by Gas Chromatography/Mass Spectrometry Chemical Profiles. Anal Chem 2013, 85 (5), 2945-2953.

27. Lu, W. Y.; Rankin, J. G.; Bondra, A.; Trader, C.; Heeren, A.; Harrington, P. D., Ignitable liquid identification using gas chromatography/mass spectrometry data by projected difference resolution mapping and fuzzy rulebuilding expert system classification. Forensic Sci Int 2012, 220 (1-3), 210218.

28. Abdi, H., Partial least squares regression and projection on latent structure regression (PLS Regression). WIREs Computational Statatistics 2010, 2 (1), 97-106.

29. Delaigle, A.; Hall, P., METHODOLOGY AND THEORY FOR PARTIAL LEAST SQUARES APPLIED TO FUNCTIONAL DATA. Annals of Statistics 2012, 40 (1), $322-352$.

30. Harrington, P. D.; Kister, J.; Artaud, J.; Dupuy, N., Automated Principal Component-Based Orthogonal Signal Correction Applied to Fused Near Infrared-Mid-infrared Spectra of French Olive Oils. Anal Chem 2009, 81 (17), 7160-7169. 
31. Harrington, P. D. B., Statistical validation of classification and calibration models using bootstrapped Latin partitions. Trac-Trends in Analytical Chemistry 2006, 25 (11), 1112-1124.

32. Sahin, S.; Isik, E.; Aybastier, O.; Demir, C., Orthogonal signal correctionbased prediction of total antioxidant activity using partial least squares regression from chromatograms. Journal of Chemometrics 2012, 26 (7), 390-399.

33. Sahin, S.; Isik, E.; Demir, C., Prediction of Total Phenolic Content in Extracts ofPrunellaSpecies from HPLC Profiles by Multivariate Calibration. ISRN Chromatography 2012, 2012, 1-7. 


\section{Table Captions}

Table 1. Total antioxidant activities of Prunella L. extracts with extraction solvents

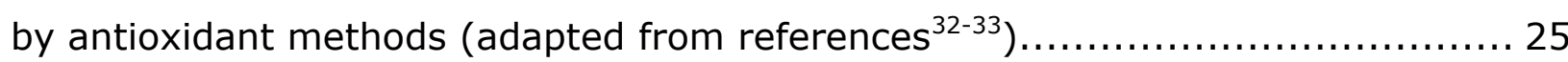

Table 2. Average coefficients of determination $R^{2}$ with confidence intervals for each assay from four different representations evaluated by PLS predictions before and

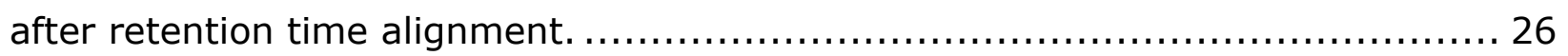

Table 3. Average root mean square error of prediction (RMSEPs) with confidence intervals for each assay from four different representations evaluated by PLS predictions before and after retention time alignment.

Table 4. RMSEP for each solvent and the ABST method. RMSEPs are given with $95 \%$ confidence intervals after retention time alignment.

Table 5. RMSEP for each solvent and the DPPH method. RMSEPs are given with $95 \%$ confidence intervals after retention time alignment.

Table 6. RMSEP for each solvent and the FC method. RMSEPs are given with $95 \%$ confidence intervals after retention time alignment. 30 


\section{Tables}

\begin{tabular}{|c|c|c|c|c|c|c|c|c|c|c|c|c|}
\hline & \multicolumn{3}{|c|}{ Prunella grandiflora L. } & \multicolumn{3}{|c|}{ Prunella laciniata L. } & \multicolumn{3}{|c|}{$\begin{array}{l}\text { Prunella orientalis } \\
\text { Bornm. }\end{array}$} & \multicolumn{3}{|c|}{ Prunella vulgarus L. } \\
\hline & M1 & M2 & M3 & M1 & M2 & M3 & M1 & M2 & M3 & M1 & M2 & M3 \\
\hline A & $\begin{array}{l}18.2 \pm \\
0.5\end{array}$ & \begin{tabular}{|l|}
$32.7 \pm$ \\
1.3
\end{tabular} & $\begin{array}{l}1.8 \pm \\
0.0\end{array}$ & $\begin{array}{l}22.5 \pm \\
0.6\end{array}$ & $\begin{array}{l}24.2 \pm \\
0.4\end{array}$ & $\begin{array}{l}2.0 \pm 0 \\
.1\end{array}$ & $\begin{array}{l}14.4 \pm \\
0.2\end{array}$ & $\begin{array}{l}26.2 \pm \\
1.5\end{array}$ & $\begin{array}{l}1.7 \pm \\
0.1\end{array}$ & \begin{tabular}{|l|}
$22.3 \pm$ \\
0.7
\end{tabular} & $\begin{array}{l}24.1 \pm \\
1.4\end{array}$ & $\begin{array}{l}4.2 \pm \\
0.3\end{array}$ \\
\hline $\begin{array}{l}\text { A } \\
A\end{array}$ & $\begin{array}{l}37.8 \pm \\
0.1\end{array}$ & \begin{tabular}{|l|}
$73.5 \pm$ \\
0.4
\end{tabular} & $\begin{array}{l}79.6 \\
\pm 0.7\end{array}$ & $\begin{array}{l}37.2 \pm \\
0.3\end{array}$ & $\begin{array}{l}73.8 \pm \\
1.1\end{array}$ & $\begin{array}{l}77.3 \pm \\
0.8\end{array}$ & $\begin{array}{l}35.4 \pm \\
0.1\end{array}$ & $\begin{array}{l}72.2 \pm \\
0.8\end{array}$ & $\begin{array}{l}63.5 \\
\pm 0.6\end{array}$ & $\begin{array}{l}37.3 \pm \\
0.2\end{array}$ & $\begin{array}{l}73.2 \pm \\
1.2 \\
\end{array}$ & $\begin{array}{l}76.5 \\
\pm 0.9 \\
\end{array}$ \\
\hline $\begin{array}{l}\text { A } \\
B\end{array}$ & $\begin{array}{l}81.7 \pm \\
1.8\end{array}$ & \begin{tabular}{|l|}
$92.9 \pm$ \\
1.0 \\
\end{tabular} & $\begin{array}{l}68.0 \\
\pm 0.6 \\
\end{array}$ & $\begin{array}{l}102.5 \\
\pm 0.7\end{array}$ & $\begin{array}{l}94.5 \pm \\
2.0\end{array}$ & $\begin{array}{l}55.8 \pm \\
0.93\end{array}$ & $\begin{array}{l}87.2 \pm \\
2.4 \\
\end{array}$ & $\begin{array}{l}86.0 \pm \\
2.0\end{array}$ & $\begin{array}{l}45.4 \\
\pm 1.2 \\
\end{array}$ & $\begin{array}{l}102.1 \\
\pm 0.2\end{array}$ & $\begin{array}{l}88.8 \pm \\
1.8 \\
\end{array}$ & $\begin{array}{l}47.1 \\
\pm 0.7\end{array}$ \\
\hline $\begin{array}{l}\mathrm{A} \\
\mathrm{E}\end{array}$ & $\begin{array}{l}31.3 \pm \\
0.1 \\
\end{array}$ & \begin{tabular}{|l|}
$67.5 \pm$ \\
1.9 \\
\end{tabular} & $\begin{array}{l}83.9 \\
\pm 0.4\end{array}$ & $\begin{array}{l}33.9 \pm \\
0.1 \\
\end{array}$ & $\begin{array}{l}67.2 \pm \\
0.3 \\
\end{array}$ & $\begin{array}{l}86.1 \pm \\
0.9 \\
\end{array}$ & $\begin{array}{l}33.6 \pm \\
0.6\end{array}$ & $\begin{array}{l}67.2 \pm \\
1.2 \\
\end{array}$ & $\begin{array}{l}70.6 \\
\pm 0.6 \\
\end{array}$ & $\begin{array}{l}33.3 \pm \\
0.1 \\
\end{array}$ & $\begin{array}{l}62.2 \pm \\
0.7 \\
\end{array}$ & $\begin{array}{l}87.3 \\
\pm 0.9 \\
\end{array}$ \\
\hline $\begin{array}{l}\mathrm{A} \\
\mathrm{H}\end{array}$ & $\begin{array}{l}1.4 \pm 0 \\
.0\end{array}$ & $\begin{array}{l}0.1 \pm 0 \\
.0 \\
\end{array}$ & $\begin{array}{l}1.4 \pm \\
0.4\end{array}$ & $\begin{array}{l}0.7 \pm 0 \\
.1 \\
\end{array}$ & $\begin{array}{l}0.1 \pm 0 \\
.1\end{array}$ & $\begin{array}{l}1.3 \pm 0 \\
.1 \\
\end{array}$ & $\begin{array}{l}1.7 \pm 0 \\
.0\end{array}$ & $\begin{array}{l}0.2 \pm 0 \\
.0\end{array}$ & $\begin{array}{l}1.6 \pm \\
0.1\end{array}$ & $\begin{array}{l}1.5 \pm 0 \\
.0\end{array}$ & $\begin{array}{l}0.1 \pm 0 \\
.0\end{array}$ & $\begin{array}{l}1.2 \pm \\
0.1\end{array}$ \\
\hline $\begin{array}{l}A \\
M\end{array}$ & $\begin{array}{l}298.2 \\
\pm 2.2 \\
\end{array}$ & $\begin{array}{l}237.9 \\
\pm 2.1 \\
\end{array}$ & $\begin{array}{l}78.0 \\
\pm 0.5 \\
\end{array}$ & $\begin{array}{l}329.6 \\
\pm 0.8 \\
\end{array}$ & $\begin{array}{l}220.5 \\
\pm 2.5 \\
\end{array}$ & $\begin{array}{l}77.0 \pm \\
0.5 \\
\end{array}$ & $\begin{array}{l}329.0 \\
\pm 1.7 \\
\end{array}$ & $\begin{array}{l}256.5 \\
\pm 2.8 \\
\end{array}$ & $\begin{array}{l}63.0 \\
\pm 0.8 \\
\end{array}$ & $\begin{array}{l}343.6 \\
\pm 2.1 \\
\end{array}$ & $\begin{array}{l}219.3 \\
\pm 4.7 \\
\end{array}$ & $\begin{array}{l}76.3 \\
\pm 1.0 \\
\end{array}$ \\
\hline $\begin{array}{l}A \\
W \\
\end{array}$ & $\begin{array}{l}201.6 \\
\pm 0.7 \\
\end{array}$ & \begin{tabular}{|l|}
103.0 \\
\pm 2.4 \\
\end{tabular} & $\begin{array}{l}30.9 \\
\pm 0.4 \\
\end{array}$ & $\begin{array}{l}208.9 \\
\pm 1.5 \\
\end{array}$ & $\begin{array}{l}107.2 \\
\pm 2.2 \\
\end{array}$ & $\begin{array}{l}32.3 \pm \\
1.2 \\
\end{array}$ & $\begin{array}{l}248.4 \\
\pm 7.0 \\
\end{array}$ & $\begin{array}{l}108.4 \\
\pm 4.1 \\
\end{array}$ & $\begin{array}{l}27.1 \\
\pm 0.9 \\
\end{array}$ & $\begin{array}{l}215.2 \\
\pm 0.9 \\
\end{array}$ & $\begin{array}{l}118.8 \\
\pm 1.7 \\
\end{array}$ & $\begin{array}{l}26.5 \\
\pm 0.6 \\
\end{array}$ \\
\hline B & $\begin{array}{l}57.1 \pm \\
3.2 \\
\end{array}$ & \begin{tabular}{|l|}
$76.6 \pm$ \\
1.7 \\
\end{tabular} & $\begin{array}{l}12.6 \\
\pm 0.5 \\
\end{array}$ & $\begin{array}{l}48.3 \pm \\
0.2 \\
\end{array}$ & $\begin{array}{l}63.0 \pm \\
0.4 \\
\end{array}$ & $\begin{array}{l}13.0 \pm \\
0.9 \\
\end{array}$ & $\begin{array}{l}44.7 \pm \\
1.0 \\
\end{array}$ & $\begin{array}{l}65.1 \pm \\
1.5 \\
\end{array}$ & $\begin{array}{l}9.6 \pm \\
0.6 \\
\end{array}$ & $\begin{array}{l}53.3 \pm \\
1.6 \\
\end{array}$ & $\begin{array}{l}53.9 \pm \\
1.5 \\
\end{array}$ & $\begin{array}{l}13.7 \\
\pm 0.7 \\
\end{array}$ \\
\hline$E$ & $\begin{array}{l}5.7 \pm 0 \\
.2 \\
\end{array}$ & \begin{tabular}{l|}
$10.4 \pm$ \\
0.2 \\
\end{tabular} & $\begin{array}{l}2.5 \pm \\
0.1 \\
\end{array}$ & $\begin{array}{l}4.1 \pm 0 \\
.5 \\
\end{array}$ & $\begin{array}{l}5.6 \pm 1 \\
.0\end{array}$ & $\begin{array}{l}1.8 \pm 0 \\
.0 \\
\end{array}$ & $\begin{array}{l}10.7 \pm \\
0.9 \\
\end{array}$ & $\begin{array}{l}11.5 \pm \\
1.1 \\
\end{array}$ & $\begin{array}{l}1.9 \pm \\
0.6 \\
\end{array}$ & $\begin{array}{l}5.6 \pm 0 \\
.4 \\
\end{array}$ & $\begin{array}{l}7.5 \pm 0 \\
.4 \\
\end{array}$ & $\begin{array}{l}2.1 \pm \\
0.3 \\
\end{array}$ \\
\hline $\mathrm{H}$ & $\begin{array}{l}0.5 \pm 0 \\
.0 \\
\end{array}$ & \begin{tabular}{|l}
$0.1 \pm 0$ \\
.0 \\
\end{tabular} & $\begin{array}{l}1.0 \pm \\
0.1 \\
\end{array}$ & $\begin{array}{l}0.4 \pm 0 \\
.0 \\
\end{array}$ & $\begin{array}{l}0.1 \pm 0 \\
.0 \\
\end{array}$ & $\begin{array}{l}1.0 \pm 0 \\
.2 \\
\end{array}$ & $\begin{array}{l}0.5 \pm 0 \\
.0 \\
\end{array}$ & $\begin{array}{l}0.1 \pm 0 \\
.0 \\
\end{array}$ & $\begin{array}{l}1.0 \pm \\
0.2 \\
\end{array}$ & $\begin{array}{l}0.8 \pm 0 \\
.0 \\
\end{array}$ & $\begin{array}{l}0.1 \pm 0 \\
.0\end{array}$ & $\begin{array}{l}1.0 \pm \\
0.3 \\
\end{array}$ \\
\hline M & $\begin{array}{l}188.6 \\
\pm 3.4 \\
\end{array}$ & \begin{tabular}{|l|}
122.5 \\
\pm 1.6 \\
\end{tabular} & $\begin{array}{l}16.9 \\
\pm 0.0 \\
\end{array}$ & $\begin{array}{l}151.2 \\
\pm 3.5 \\
\end{array}$ & $\begin{array}{l}134.2 \\
\pm 5.1 \\
\end{array}$ & $\begin{array}{l}11.7 \pm \\
1.4 \\
\end{array}$ & $\begin{array}{l}201.0 \\
\pm 0.4 \\
\end{array}$ & $\begin{array}{l}118.8 \\
\pm 1.6\end{array}$ & $\begin{array}{l}8.4 \pm \\
0.6 \\
\end{array}$ & $\begin{array}{l}166.1 \\
\pm 4.2 \\
\end{array}$ & $\begin{array}{l}151.8 \\
\pm 1.6 \\
\end{array}$ & $\begin{array}{l}11.5 \\
\pm 0.5 \\
\end{array}$ \\
\hline W & $\begin{array}{l}123.4 \\
\pm 0.9\end{array}$ & \begin{tabular}{|l}
$97.2 \pm$ \\
1.9 \\
\end{tabular} & $\begin{array}{l}24.6 \\
\pm 0.5 \\
\end{array}$ & $\begin{array}{l}121.9 \\
\pm 1.0\end{array}$ & $\begin{array}{l}84.0 \pm \\
0.8 \\
\end{array}$ & $\begin{array}{l}20.2 \pm \\
1.3 \\
\end{array}$ & $\begin{array}{l}131.8 \\
\pm 1.9\end{array}$ & $\begin{array}{l}85.9 \pm \\
1.2\end{array}$ & $\begin{array}{l}11.0 \\
\pm 0.1 \\
\end{array}$ & $\begin{array}{l}117.7 \\
\pm 0.6\end{array}$ & $\begin{array}{l}92.3 \pm \\
1.5 \\
\end{array}$ & $\begin{array}{l}15.5 \\
\pm 0.0 \\
\end{array}$ \\
\hline \multicolumn{13}{|c|}{$\begin{array}{l}\text { Abbreviations: Methods: M1 (mg TE/g); The ABST Method, M2 (mg TE/g); The } \\
\text { DPPH Method, M3 (mg GAE/g); The FC Method. Solvents: A; Acetonitrile, AA; } \\
\text { Acidic Acetonitrile, AB; Acidic Butanol, AE; Acidic Ethyl Acetate, AH; Acidic Hexane, } \\
\text { AM; Acidic Methanol, AW; Acidic Water, B; Butanol, E; Ethyl Acetate, H; Hexane, M; } \\
\text { Methanol, W; Water. }\end{array}$} \\
\hline
\end{tabular}




\begin{tabular}{|c|c|c|c|c|c|c|}
\hline & \multicolumn{2}{|c|}{ ABST } & \multicolumn{2}{|c|}{ DPPH } & \multicolumn{2}{|c|}{$\mathrm{FC}$} \\
\hline & Before & After & Before & After & Before & After \\
\hline R1 & $0.936 \pm 0.003$ & $0.943 \pm 0.008$ & $0.911 \pm 0.003$ & $0.91 \pm 0.01$ & $0.969 \pm 0.002$ & $0.963 \pm 0.006$ \\
\hline R2 & $0.48 \pm 0.04$ & $0.74 \pm 0.08$ & $0.60 \pm 0.03$ & $0.76 \pm 0.06$ & $0.919 \pm 0.003$ & $0.944 \pm 0.006$ \\
\hline R3 & $0.873 \pm 0.005$ & $0.92 \pm 0.01$ & $0.866 \pm 0.006$ & $0.89 \pm 0.02$ & $0.957 \pm 0.002$ & $0.954 \pm 0.006$ \\
\hline R4 & $0.935 \pm 0.002$ & $0.93 \pm 0.02$ & $0.903 \pm 0.004$ & $0.89 \pm 0.02$ & $0.885 \pm 0.004$ & $0.90 \pm 0.01$ \\
\hline & & . & & & al in & $\begin{array}{l}\text { es, R2; } \\
\text { Lambda }\end{array}$ \\
\hline
\end{tabular}




\begin{tabular}{|c|c|c|c|c|c|c|}
\hline \multirow[t]{2}{*}{ RMSEP } & \multicolumn{2}{|c|}{ ABST (mg TE/g) } & \multicolumn{2}{|c|}{$\mathrm{DPPH}(\mathrm{mg} \mathrm{TE} / \mathrm{g})$} & \multicolumn{2}{|c|}{$\mathrm{FC}(\mathrm{mg} \mathrm{GAE} / \mathrm{g})$} \\
\hline & Before & After & Before & After & Before & After \\
\hline R1 & $26.8 \pm 0.4$ & $24 \pm 1$ & $20.6 \pm 0.3$ & $19 \pm 1$ & $5.9 \pm 0.1$ & $5.9 \pm 0.4$ \\
\hline R2 & $85 \pm 2$ & $50 \pm 6$ & $47 \pm 1$ & $31 \pm 3$ & $9 \pm 1$ & $7.3 \pm 0.4$ \\
\hline R3 & $27.9 \pm 0.5$ & $28 \pm 2$ & $25.2 \pm 0.5$ & $21 \pm 1$ & $6.9 \pm 0.1$ & $6.6 \pm 0.4$ \\
\hline R4 & $26.7 \pm 0.4$ & $25 \pm 3$ & $21.7 \pm 0.3$ & $21 \pm 2$ & $10.9 \pm 0.1$ & $10 \pm 1$ \\
\hline \multicolumn{7}{|c|}{$\begin{array}{l}\text { Abbreviations: R1; The entire two-way chromatographic-spectral images, R2; } \\
\text { Averaged UV spectrum, R3; Total absorbance chromatogram, and R4; Lambda } \\
\max \left(\lambda_{\max }\right) \text { chromatogram. }\end{array}$} \\
\hline
\end{tabular}




\begin{tabular}{|c|c|c|c|c|c|}
\hline & $\begin{array}{l}\text { Prunella } \\
\text { grandiflora L. } \\
(\mathrm{mg} \mathrm{TE} / \mathrm{g})\end{array}$ & $\begin{array}{l}\text { Prunella } \\
\text { laciniata L. } \\
\text { (mg TE/g) }\end{array}$ & $\begin{array}{l}\text { Prunella } \\
\text { orientalis Bornm. } \\
\text { (mg TE/g) }\end{array}$ & $\begin{array}{l}\text { Prunella } \\
\text { vulgarus L. } \\
\text { (mg TE/g) }\end{array}$ & \\
\hline$A$ & $3 \pm 2$ & $2 \pm 1$ & $2 \pm 1$ & $3 \pm 2$ & \\
\hline AA & $22 \pm 11$ & $23 \pm 8$ & $57 \pm 12$ & $17 \pm 3$ & \\
\hline$A B$ & $25 \pm 3$ & $33 \pm 3$ & $4 \pm 2$ & $22 \pm 4$ & \\
\hline $\mathrm{AE}$ & $15 \pm 7$ & $2 \pm 2$ & $7 \pm 4$ & $30 \pm 3$ & \\
\hline $\mathrm{AH}$ & $3 \pm 1$ & $7 \pm 2$ & $2 \pm 1$ & $3 \pm 2$ & \\
\hline AM & $56 \pm 13$ & $40 \pm 6$ & $45 \pm 12$ & $16 \pm 5$ & \\
\hline AW & $20 \pm 11$ & $48 \pm 3$ & $68 \pm 4$ & $34 \pm 7$ & \\
\hline $\mathrm{B}$ & $12 \pm 5$ & $3 \pm 1$ & $5 \pm 4$ & $5 \pm 2$ & \\
\hline E & $29 \pm 5$ & $16 \pm 2$ & $8 \pm 2$ & $17 \pm 7$ & \\
\hline $\mathrm{H}$ & $4 \pm 1$ & $7 \pm 2$ & $2 \pm 1$ & $10 \pm 3$ & \\
\hline M & $17 \pm 8$ & $16 \pm 5$ & $28 \pm 6$ & $11 \pm 4$ & \\
\hline W & $15 \pm 7$ & $24 \pm 7$ & $9 \pm 4$ & $12 \pm 5$ & \\
\hline \multicolumn{6}{|c|}{$\begin{array}{l}\text { Solvents: A; Acetonitrile, AA; Acidic Acetonitrile, AB; Acidic Butanol, AE; Acidic } \\
\text { Ethyl Acetate, AH; Acidic Hexane, AM; Acidic Methanol, AW; Acidic Water, B; } \\
\text { Butanol, E; Ethyl Acetate, H; Hexane, M; Methanol, W; Water. }\end{array}$} \\
\hline
\end{tabular}




\begin{tabular}{|c|c|c|c|c|c|}
\hline & $\begin{array}{l}\text { Prunella } \\
\text { grandiflora } \\
\text { L. } \\
(\mathrm{mg} \mathrm{TE} / \mathrm{g})\end{array}$ & $\begin{array}{l}\text { Prunella } \\
\text { laciniata L. } \\
(\mathrm{mg} \mathrm{TE} / \mathrm{g})\end{array}$ & $\begin{array}{l}\text { Prunella } \\
\text { orientalis Bornm. } \\
(\mathrm{mg} \mathrm{TE} / \mathrm{g})\end{array}$ & $\begin{array}{l}\text { Prunella } \\
\text { vulgarus L. } \\
\text { (mg TE/g) }\end{array}$ & \\
\hline A & $4 \pm 1$ & $8 \pm 2$ & $3 \pm 1$ & $6 \pm 3$ & \\
\hline AA & $11 \pm 6$ & $8 \pm 3$ & $14 \pm 8$ & $14 \pm 3$ & \\
\hline$A B$ & $9 \pm 4$ & $22 \pm 2$ & $3 \pm 1$ & $20 \pm 3$ & \\
\hline $\mathrm{AE}$ & $9 \pm 4$ & $3 \pm 2$ & $5 \pm 2$ & $11 \pm 4$ & \\
\hline $\mathrm{AH}$ & $2 \pm 1$ & $5 \pm 1$ & $1 \pm 1$ & $2 \pm 1$ & \\
\hline$A M$ & $28 \pm 10$ & $18 \pm 7$ & $54 \pm 4$ & $46 \pm 4$ & \\
\hline AW & $8 \pm 4$ & $24 \pm 2$ & $11 \pm 3$ & $21 \pm 8$ & \\
\hline B & $23 \pm 7$ & $5 \pm 1$ & $14 \pm 6$ & $17 \pm 3$ & \\
\hline$E$ & $19 \pm 4$ & $25 \pm 2$ & $6 \pm 2$ & $15 \pm 7$ & \\
\hline $\mathrm{H}$ & $5 \pm 2$ & $3 \pm 2$ & $2 \pm 1$ & $7 \pm 3$ & \\
\hline$M$ & $20 \pm 6$ & $41 \pm 6$ & $23 \pm 8$ & $29 \pm 9$ & \\
\hline W & $35 \pm 7$ & $40 \pm 4$ & $11 \pm 4$ & $8 \pm 5$ & \\
\hline \multicolumn{6}{|c|}{$\begin{array}{l}\text { Solvents: A; Acetonitrile, AA; Acidic Acetonitrile, AB; Acidic Butanol, AE; Acidic } \\
\text { Ethyl Acetate, AH; Acidic Hexane, AM; Acidic Methanol, AW; Acidic Water, B; } \\
\text { Butanol, E; Ethyl Acetate, H; Hexane, M; Methanol, W; Water. }\end{array}$} \\
\hline
\end{tabular}




\begin{tabular}{|c|c|c|c|c|}
\hline & $\begin{array}{l}\text { Prunella } \\
\text { grandiflora } \\
\text { L. } \\
\text { (mg GAE/g) }\end{array}$ & $\begin{array}{l}\text { Prunella } \\
\text { laciniata L. } \\
\text { (mg GAE/g) }\end{array}$ & $\begin{array}{l}\text { Prunella } \\
\text { orientalis Bornm. } \\
\text { (mg GAE/g) }\end{array}$ & $\begin{array}{l}\text { Prunella } \\
\text { vulgarus L. } \\
\text { (mg GAE/g) }\end{array}$ \\
\hline A & $3 \pm 1$ & $3 \pm 1$ & $2 \pm 1$ & $2 \pm 1$ \\
\hline AA & $2 \pm 1$ & $8 \pm 3$ & $2 \pm 1$ & $13 \pm 1$ \\
\hline$A B$ & $7 \pm 2$ & $2 \pm 1$ & $5 \pm 1$ & $2 \pm 1$ \\
\hline $\mathrm{AE}$ & $7 \pm 3$ & $5 \pm 1$ & $3 \pm 2$ & $18 \pm 1$ \\
\hline $\mathrm{AH}$ & $1 \pm 1$ & $1 \pm 1$ & $1 \pm 1$ & $2 \pm 1$ \\
\hline$A M$ & $9 \pm 3$ & $8 \pm 3$ & $5 \pm 2$ & $10 \pm 4$ \\
\hline AW & $3 \pm 1$ & $1 \pm 1$ & $1 \pm 1$ & $3 \pm 2$ \\
\hline B & $3 \pm 2$ & $4 \pm 1$ & $2 \pm 1$ & $2 \pm 1$ \\
\hline$E$ & $1 \pm 1$ & $2 \pm 1$ & $0.8 \pm 0.3$ & $5 \pm 2$ \\
\hline $\mathrm{H}$ & $4 \pm 1$ & $2 \pm 1$ & $3 \pm 1$ & $4 \pm 1$ \\
\hline M & $5 \pm 3$ & $4 \pm 2$ & $10 \pm 1$ & $5 \pm 1$ \\
\hline W & $14 \pm 2$ & $8 \pm 2$ & $12 \pm 3$ & $7 \pm 3$ \\
\hline
\end{tabular}

Solvents: A; Acetonitrile, AA; Acidic Acetonitrile, AB; Acidic Butanol, AE; Acidic Ethyl Acetate, AH; Acidic Hexane, AM; Acidic Methanol, AW; Acidic Water, B; Butanol, E; Ethyl Acetate, H; Hexane, M; Methanol, W; Water. 


\section{Figure Captions}

Figure 1. The total absorbance chromatograms before (top) and after (bottom) retention time alignment.

Figure 2. The total absorbance chromatograms before (top) and after (bottom) retention time alignment zoomed in to $25-30 \mathrm{~min}$.

Figure 3. The two-way representation of the dataset of Prunella grandiflora L. species extracted with acetonitrile solvent based on chromatographic and UV spectral measurements after retention time alignment.

Figure 4. Chromatogram (top) and UV spectrum (bottom) of 4 different Prunella L. species prepared with 12 extraction solvents (total 48 samples). 36

Figure 5. Correlation values $\left(R^{2}\right)$ of ABST (blue circle), DPPH (red multiplication), and FC (green square) antioxidant methods observed based on the two-way chromatographic-spectral images. Measured values of total antioxidant activity of Prunella L. species are from experimental results. Predicted values of total antioxidant activity of Prunella L. species were obtained from 10:4 bootstrapped Latin partitions. The error bars are $95 \%$ confidence intervals.

Figure 6. Correlation values $\left(R^{2}\right)$ of the ABST (blue circle), the DPPH (red multiplication), and the FC (green square) antioxidant methods observed based on UV spectra. Measured values of total antioxidant activity of Prunella L. species are from experimental results. Predicted values of total antioxidant activity of Prunella L. species were obtained from 10:4 
bootstrapped Latin partitions. The error bars are $95 \%$ confidence intervals.

Figure 7. Correlation values $\left(R^{2}\right)$ of the ABST (blue circle), the DPPH (red multiplication), and the FC (green square) antioxidant methods observed based only on the total absorbance chromatogram. Measured values of total antioxidant activity of Prunella L. species are from experimental results. Predicted values of total antioxidant activity of Prunella L. species were obtained from 10:4 bootstrapped Latin partitions. The error bars are 95\% confidence intervals. 39

Figure 8. Correlation values $\left(R^{2}\right)$ of the ABST (blue circle), the DPPH (red multiplication), and the FC (green square) antioxidant methods observed based on PLS calibration of the lambda $\max \left(\lambda_{\max }\right)$ chromatographic data. Measured values of total antioxidant activity of Prunella L. species are from experimental results. Predicted values of total antioxidant activity of Prunella L. species were obtained from 10:4 bootstrapped Latin partitions. The error bars are $95 \%$ confidence intervals. 40 
Figures
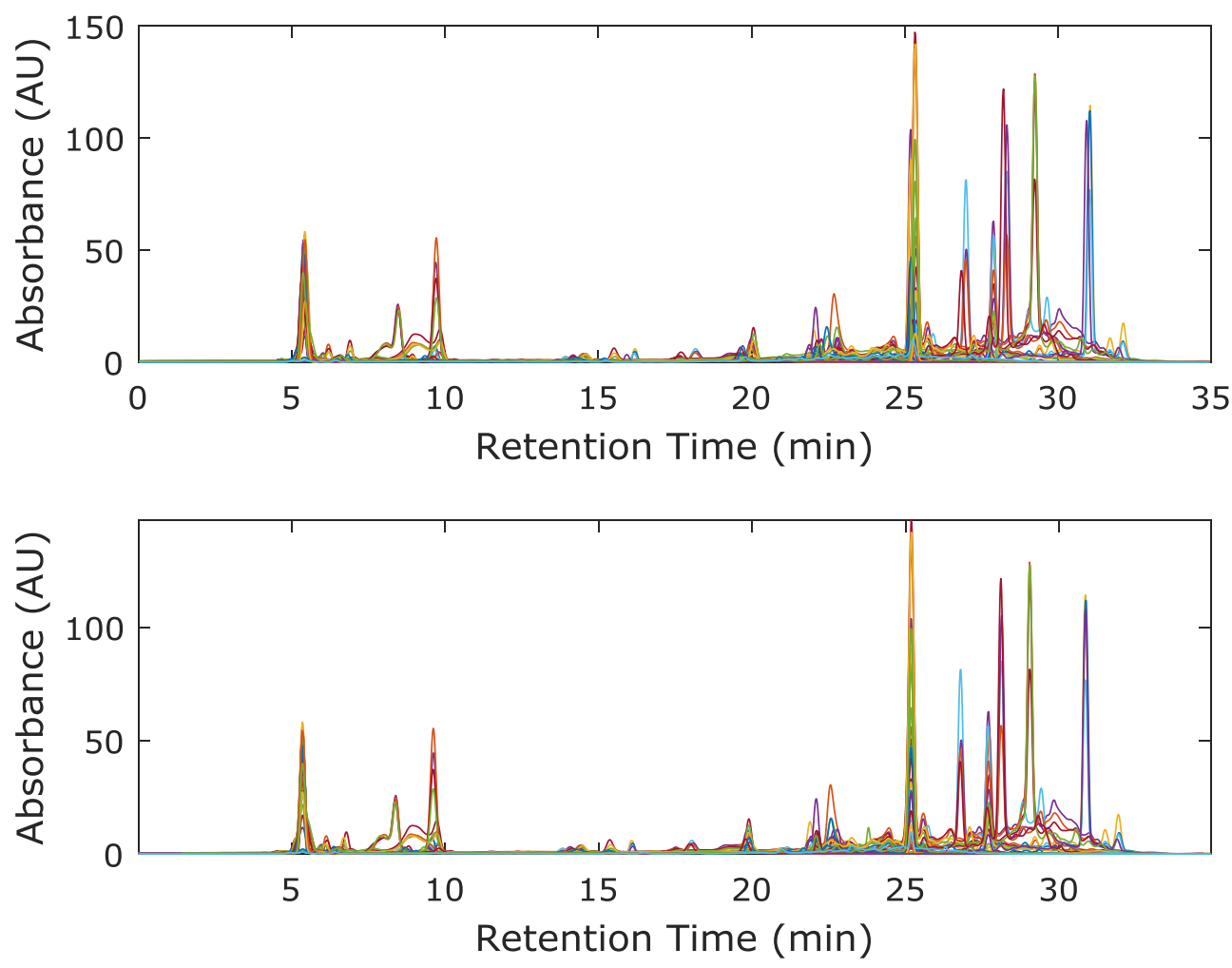

Figure 1. The total absorbance chromatograms before (top) and after (bottom) retention time alignment. 

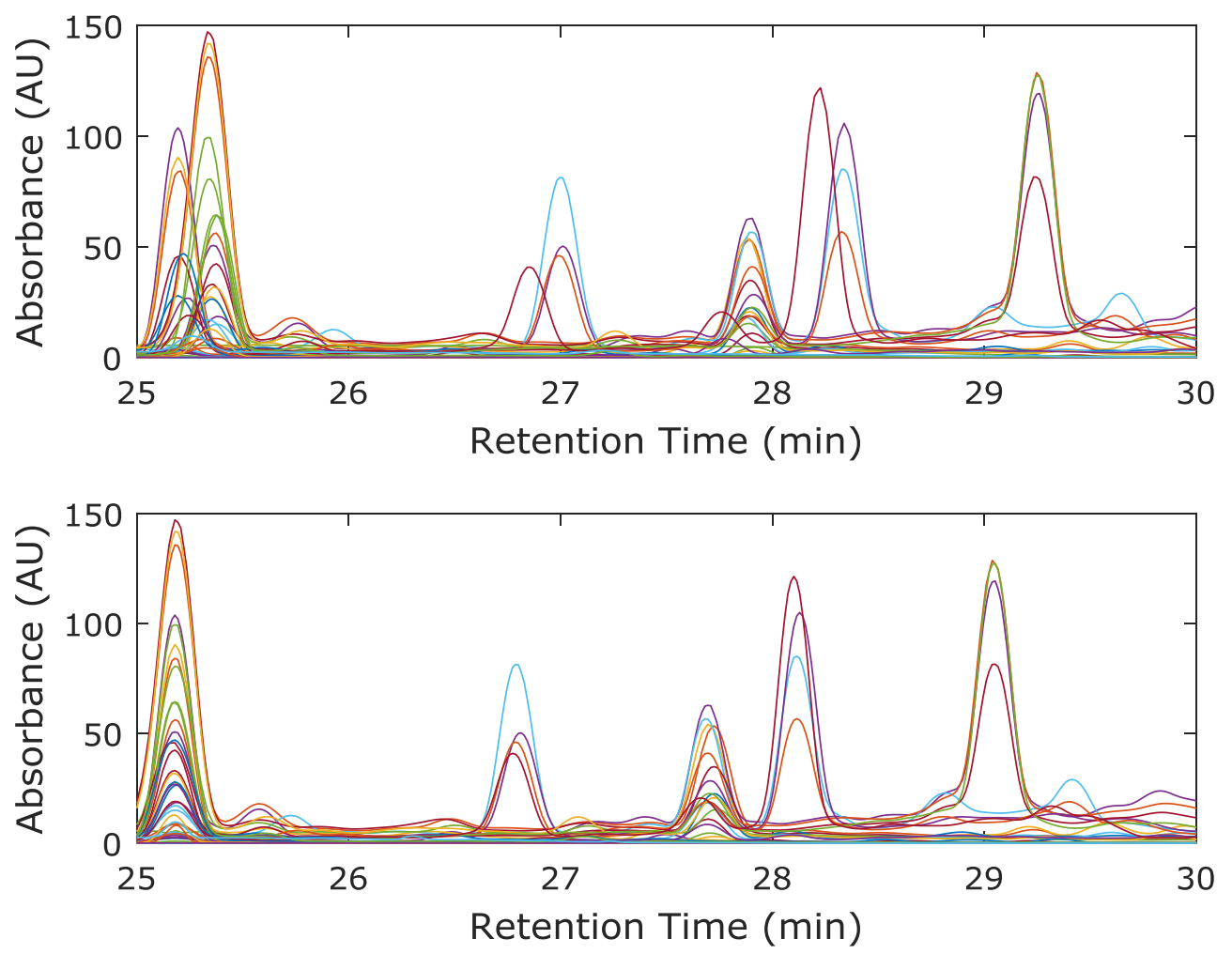

Figure 2. The total absorbance chromatograms before (top) and after (bottom) retention time alignment zoomed in to 25-30 min. 


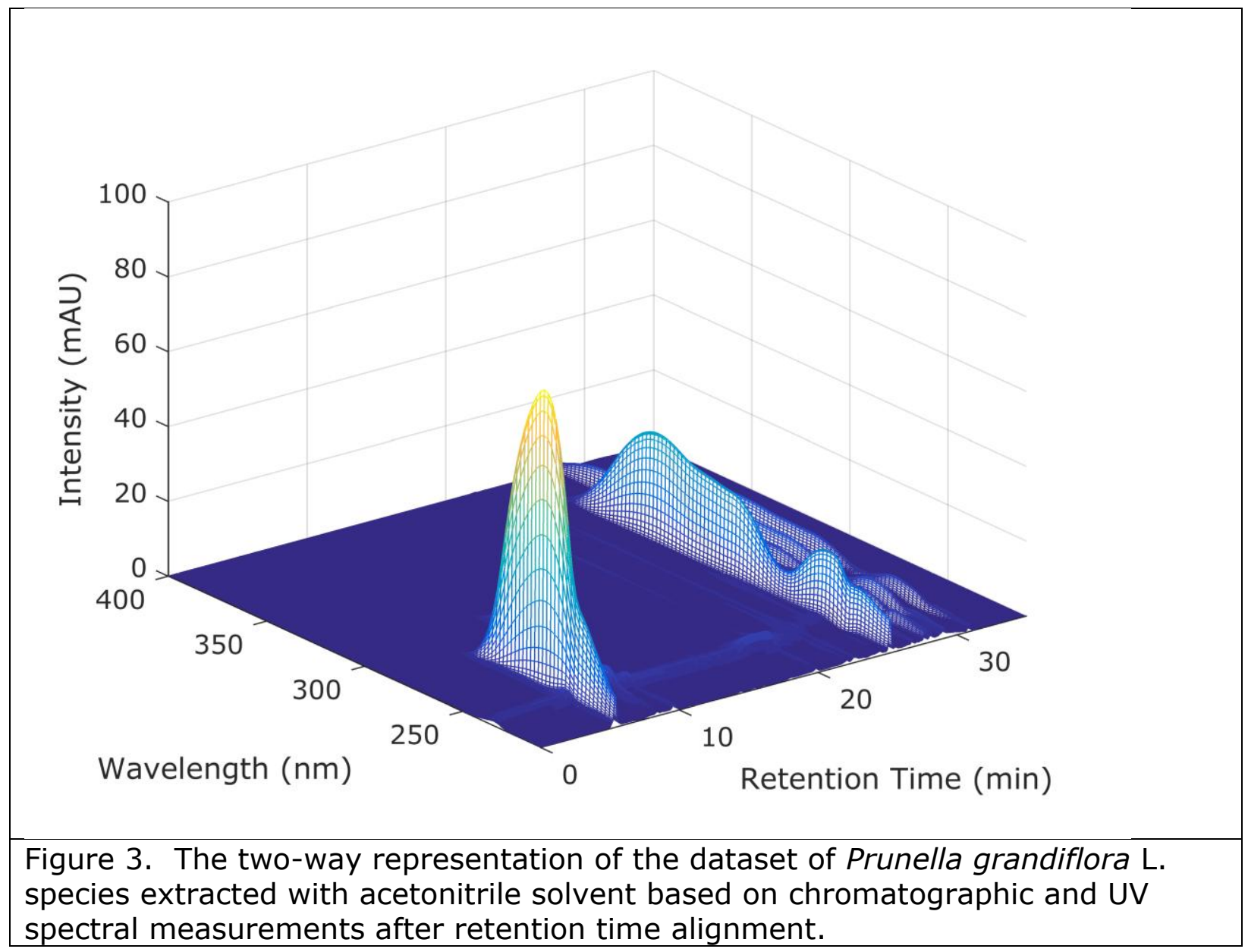




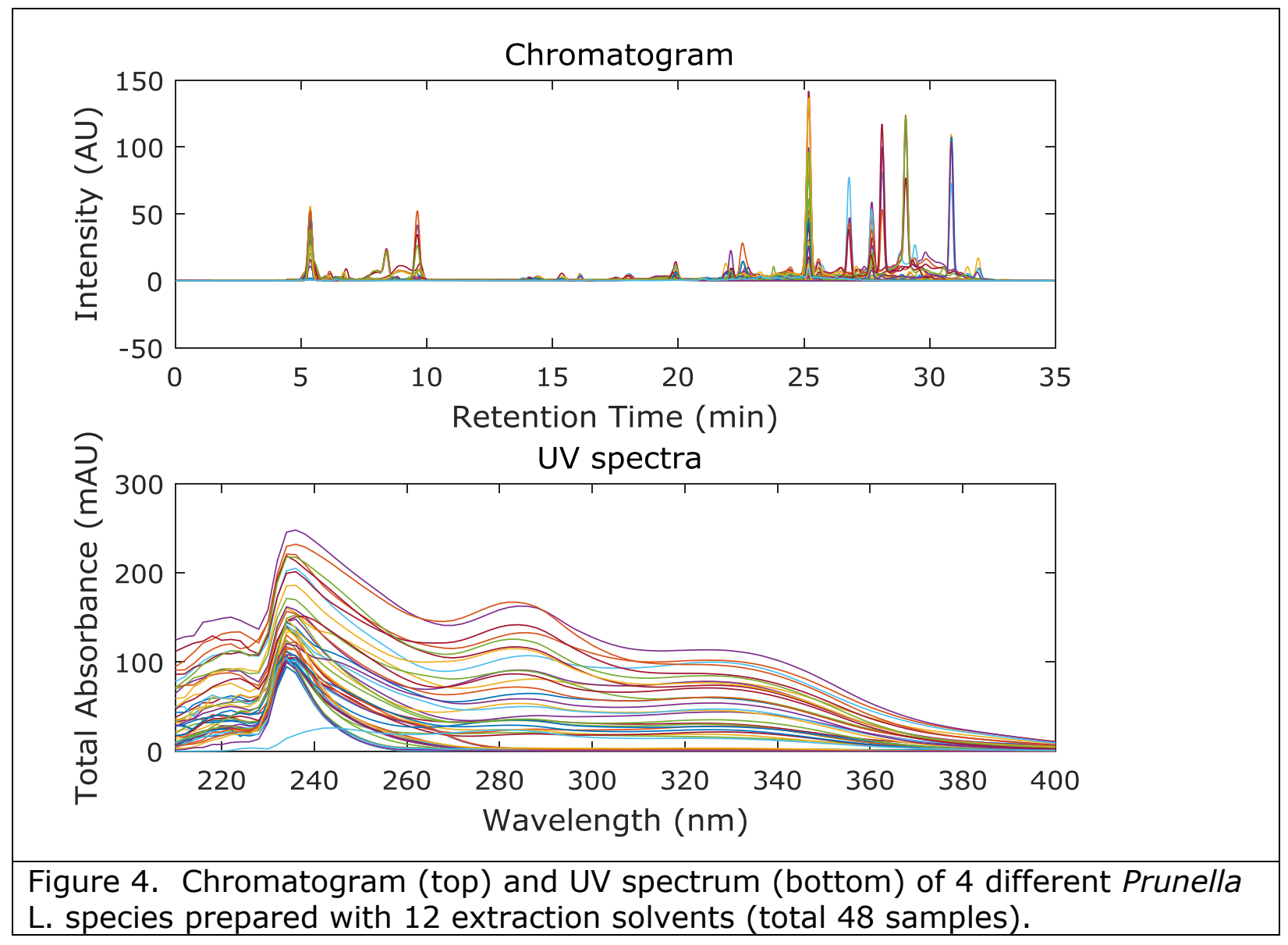




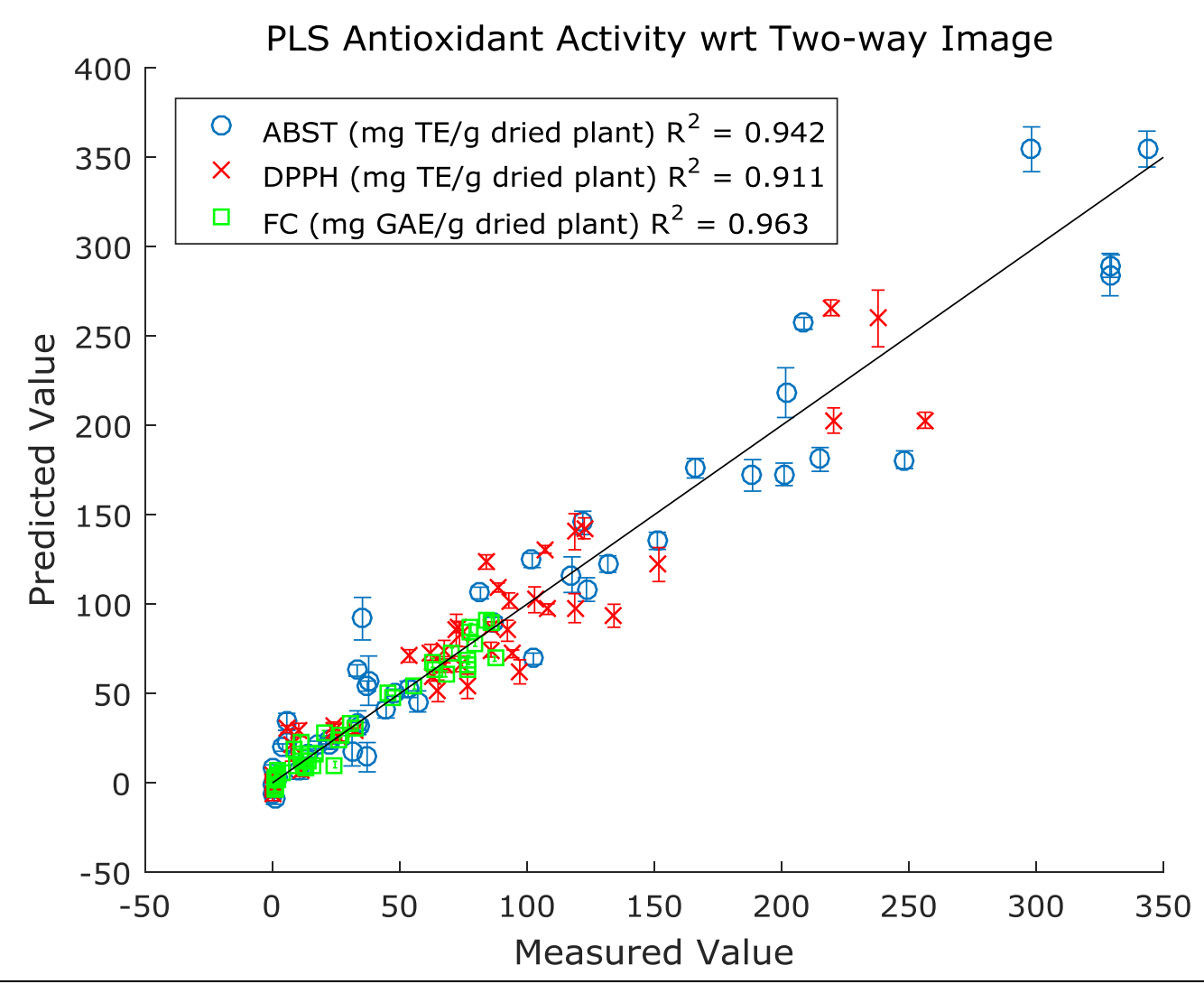

Figure 5. Correlation values $\left(R^{2}\right)$ of ABST (blue circle), DPPH (red multiplication), and FC (green square) antioxidant methods observed based on the two-way chromatographic-spectral images. Measured values of total antioxidant activity of Prunella L. species are from experimental results. Predicted values of total antioxidant activity of Prunella L. species were obtained from 10:4 bootstrapped Latin partitions. The error bars are $95 \%$ confidence intervals. 


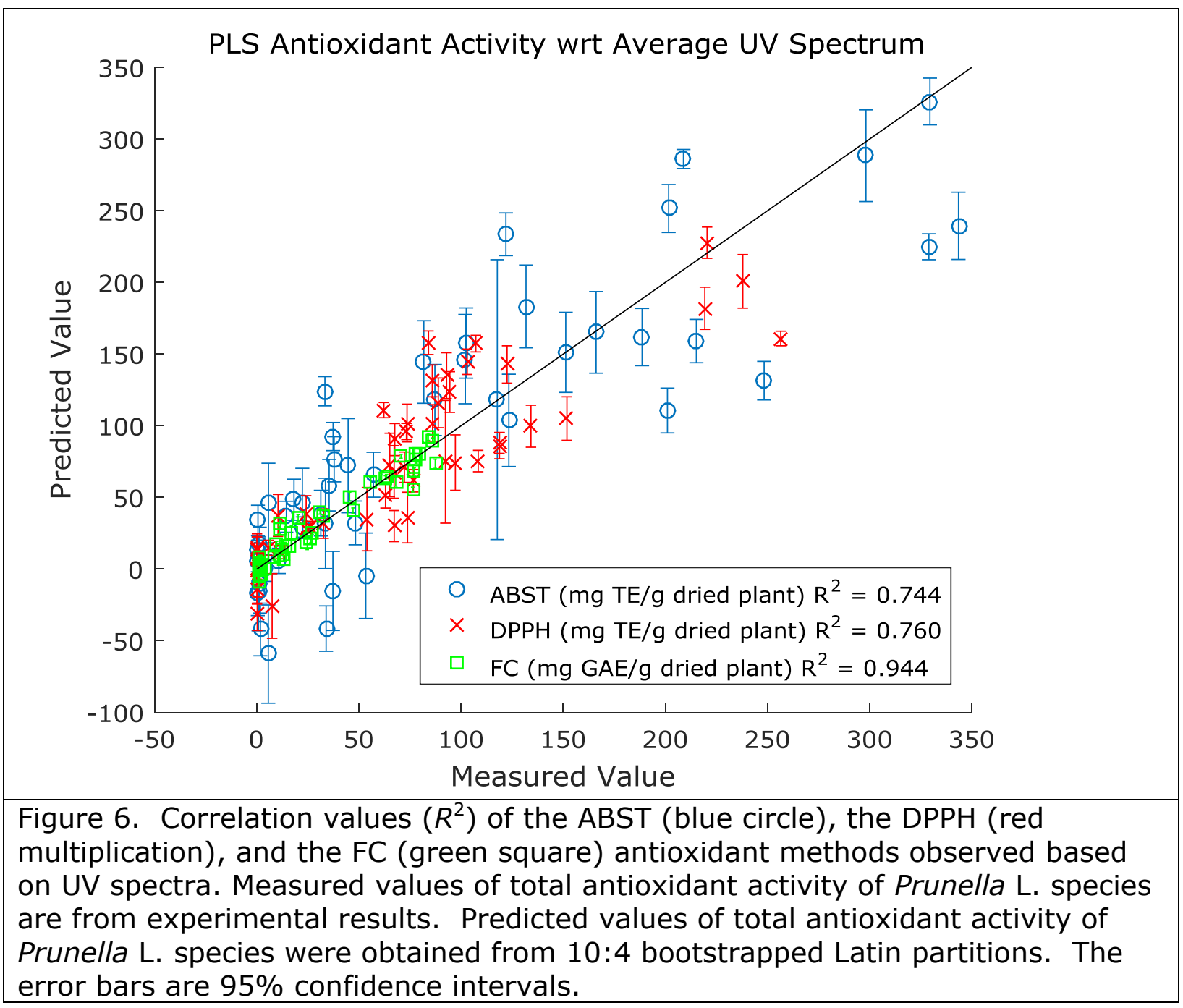




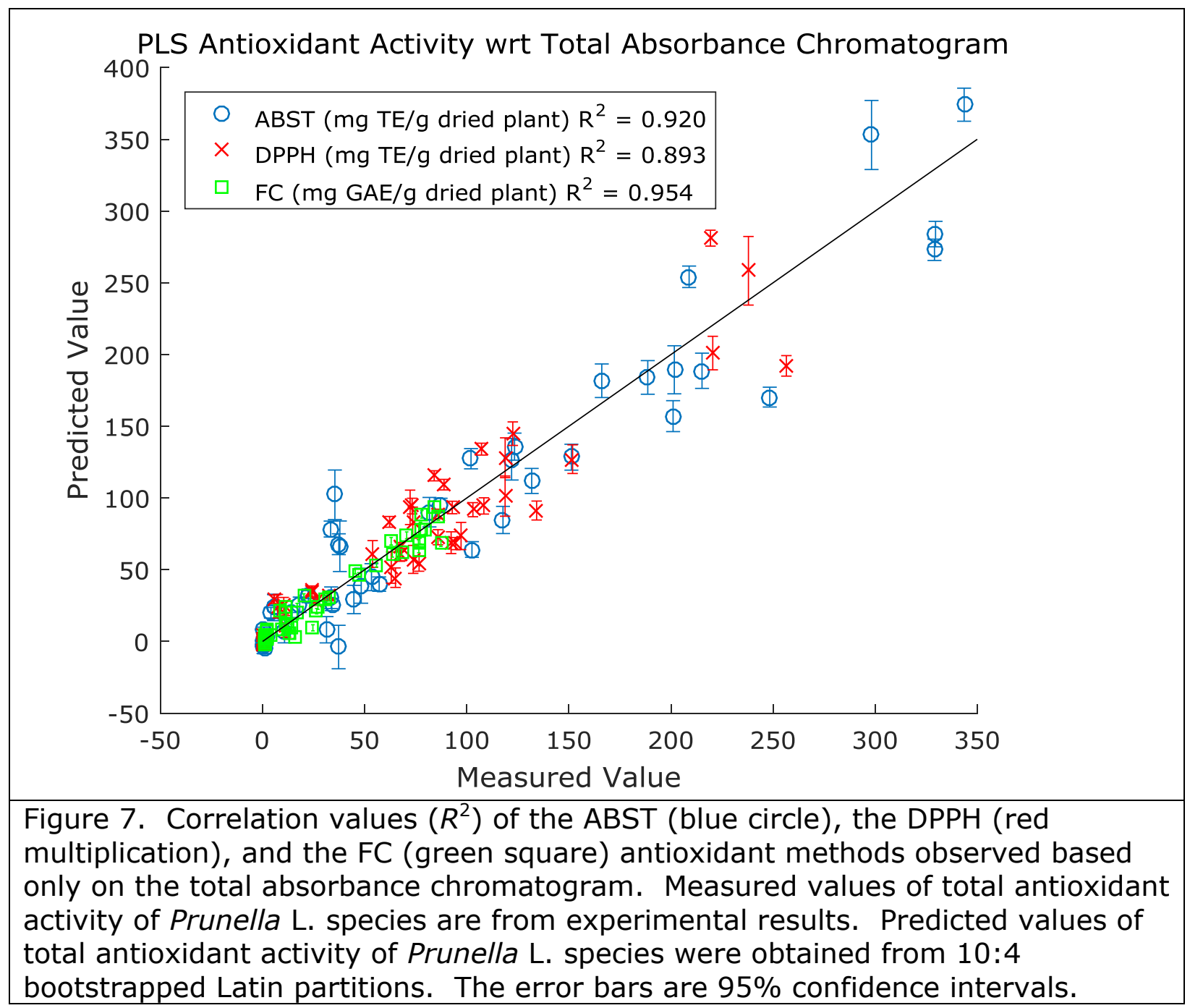




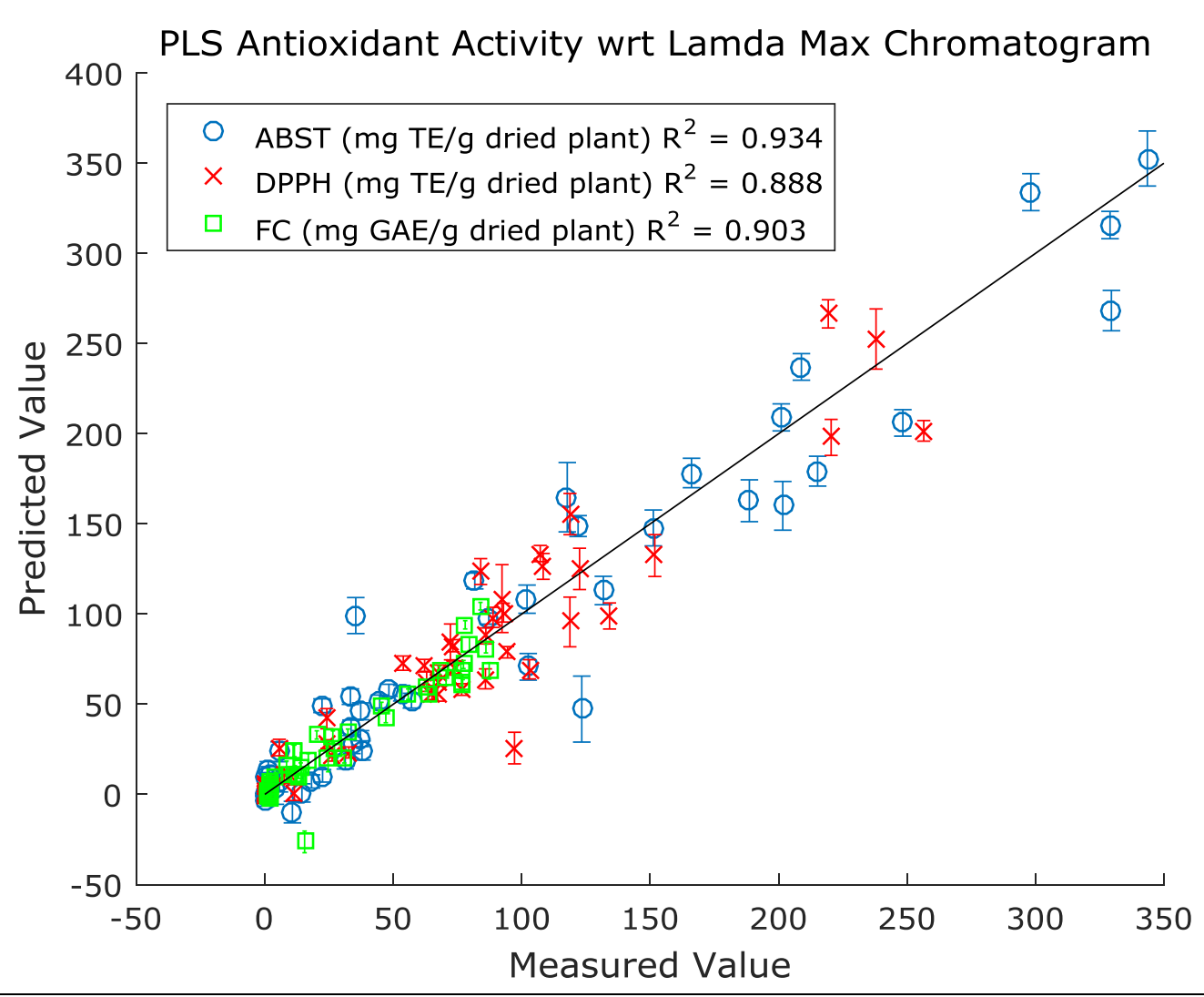

Figure 8. Correlation values $\left(R^{2}\right)$ of the ABST (blue circle), the DPPH (red multiplication), and the FC (green square) antioxidant methods observed based on PLS calibration of the lambda max $\left(\lambda_{\max }\right)$ chromatographic data. Measured values of total antioxidant activity of Prunella L. species are from experimental results. Predicted values of total antioxidant activity of Prunella L. species were obtained from 10:4 bootstrapped Latin partitions. The error bars are 95\% confidence intervals. 